\title{
Nasopharyngeal Undifferentiated Carcinoma
}

National Cancer Institute

\section{Source}

National Cancer Institute. Nasopharyngeal Undifferentiated Carcinoma. NCI Thesaurus.

Code C8023.

A nonkeratinizing nasopharyngeal carcinoma characterized by the presence of large cells with vesicular nuclei and prominent nucleoli, a syncytial growth pattern, and a lymphoplasmacytic infiltrate. 